\title{
Effect of Lentinus strigosus extract on the food intake and locomotion of N2 wild strain Caenorhabditis elegans as model for obesity
}

\author{
Yusela Kris Aquino, Rich Milton Dulay*, Sofronio Kalaw \\ Bioassay Laboratory, Department of Biological Sciences, College of Science, Central Luzon State University, Science City of Muñoz, Nueva Ecija, Philippines.
}

\section{ARTICLE INFO \\ Received on: 24/05/2020 \\ Accepted on: 16/10/2020 \\ Available online: 05/12/2020}

\section{Key words:}

Lentinus strigosus,

pharyngeal behavior assay,

locomotion, nematode,

obesity.

\begin{abstract}
Lentinus strigosus is a nutritious and medicinal mushroom. This article highlights the effects of the fruiting body ethanolic extract of $L$. strigosus on the survival, food intake, and locomotion of N2 wild strain nematode, Caenorhabditis elegans, an animal model for obesity. Nematodes at L4 stage cultured on nematode growth medium (NGM) plates with Escherichia coli OP50 strain were treated with the different concentrations of mushroom extract (10, 100, 300, and $1,000 \mu \mathrm{g} / \mathrm{ml}$ ) and dimethyl sulfoxide (DMSO) (1\%) at varying times of exposure. Nematode lethality assay revealed that as the extract concentration increased and exposure prolonged, the percentage survival decreased. None of the extract concentrations showed 50\% mortality; thus, it is considered safe to proceed to bioactivity assays. The increasing concentration of extract caused not only the decrease in the pharyngeal pumping rate (food intake) but also the increase in both reversal (dwelling) and body bend (roaming) movements of C. elegans. The dwelling and roaming locomotion of $300 \mu \mathrm{g} / \mathrm{ml}$ and $1,000 \mu \mathrm{g} / \mathrm{ml}$ extract-treated nematodes were significantly higher after 48 and 120 hours, respectively. It was also observed that nematodes treated with extract spent less time in the dwelling mode after 120 hours of exposure. Therefore, the fruiting body ethanolic extract of L. strigosus has an appetite-suppressing effect, which suggests a promising potential of this mushroom as a natural and effective remedy to prevent obesity.
\end{abstract}

\section{INTRODUCTION}

Obesity is one of the major health problems around the world (Antipatis and Gill, 2001). It is characterized by excessive fat accumulation and storage in the body (Mohamed et al., 2014) due to the lack of physical activity and excessive intake of food. This condition could trigger various health problems including diabetes mellitus, cardiovascular diseases, certain types of cancer, osteoarthritis, asthma, and obstructive sleep apnea (Haslam and James, 2005; Poulain et al., 2006; World Health Organization, 2008). In the Philippines, a joint study by the United Nations International Children's Emergency Fund, the World Health Organization, and Association of Southeast Asian Nations showed that obesity among children below 5 years jumped $400 \%$, and from

\section{*Corresponding Author}

Rich Milton Dulay, Bioassay Laboratory, Department of Biological

Sciences, College of Science, Central Luzon State University,

Science City of Muñoz, Nueva Ecija, Philippines.

E-mail: richmiltondulay@clsu.edu.ph
$1 \%$ prevalence in 1992 to $5 \%$ in 2013 above 18 years $(23.6 \%)$ were overweight. Some solutions and treatments have been developed by researchers and medical practitioners. For instance, Lau et al. (2007) stated that dieting and physical exercises are the main treatments for obesity. Moreover, medications, such as liraglutide, naltrexone-bupropion, and leptin supplements, are also being used in reducing fat gain (Tsai et al., 2013). In addition, bariatric surgery is considered to be the most effective treatment for obesity (Colquitt et al., 2014). However, these treatments are expensive and risky. Hence, continuous search for effective and natural alternatives for obesity is imperative.

Mushrooms have been of interest because of their nutritional and medicinal properties (De Silva et al., 2012). Lentinus strigosus is a wood-rotting edible Philippine mushroom that possesses nutritional and medicinal properties (Dulay and Pamiloza, 2018). The optimum culture condition for efficient mycelial growth and the enriched cultivation of fruiting bodies of $L$. strigosus using rice straw and sawdust-based substrate have been demonstrated (Dulay and Garcia, 2017; Dulay et al., 2017). The fruiting bodies of L. strigosus contain crude protein, 
crude fat, reducing sugar, fiber, soluble polysaccharides, dietary fiber, carbohydrates, minerals such as potassium, phosphorous, magnesium, iron, calcium, and zinc, and bioactive metabolites like saponins, alkaloids, flavonoids, anthraquinones, anthrones, phenols, steroids, and coumarins, and ethanol extract of this mushroom also exhibits antioxidant, antibacterial, and teratogenic activities (Dulay and Pamiloza, 2018). L. strigosus is a promising source of natural and functional food, which presumably possesses antiobesity activities.

In order to elucidate the antiobesity property of $L$. strigosus, it is vital to use an animal model that is relatively simple but with characteristics of human obesity. Caenorhabditis elegans, a nematode, is a pertinent model organism to study fat biology (Hashmi et al., 2013; McKay et al., 2003). They deposit fat for energy storage along their intestinal tract that can be distinctly visualized because of their transparent bodies (Ashrafi, 2007; Zheng et al., 2014). Previous works have successfully determined the genes responsible for the accumulation of fat with possible applications to human obesity (Mak et al., 2006; Srinivasan et al., 2008; Yen et al., 2010). These properties make a C. elegans model a reliable and important tool in studies of antiobesity activities.

With the aim to establish the health benefits of $L$. strigosus, our team has elucidated the effect of the ethanol extract of this mushroom on the pharyngeal behavior and locomotion of C. elegans as an animal model for human obesity.

\section{MATERIALS AND METHODS}

\section{Source and cultivation of mushroom}

Pure culture of $L$. strigosus was obtained from the culture collections of the Bioassay Laboratory, Department of Biological Sciences, Central Luzon State University, Science City of Muñoz, Nueva Ecija, Philippines. The fruiting bodies were mass produced similar to the process of cultivation described by Dulay and Garcia (2017).

\section{Source of chemicals and reagents}

DMSO, 95\% ethanol, $\mathrm{NaCl}$, peptone, powdered cholesterol, $1 \mathrm{M} \mathrm{KPO}_{4}$ buffer, $\mathrm{pH} 6.0$, and $1 \mathrm{M} \mathrm{MgSO}_{4}$ were purchased from Puljed Trading, Bambang District, Sta. Cruz, Manila, Philippines.

\section{Extraction and treatment preparation}

The fresh fruiting bodies of L. strigosus were air-dried and pulverized using a blender. Ten grams of the powdered sample was soaked in 11 of $95 \%$ ethanol [a good solvent for polyphenol extraction (Do et al., 2014)] for 48 hours. The filtrate was obtained using Whatman filter paper No. 2 and subsequently concentrated to dryness in a rotary evaporator (IKA ${ }^{\mathrm{TM}}$ RV10 Digital, USA). The extract yield was determined. $300 \mathrm{ml}$ of each extract concentration at $10,100,300$, and $1,000 \mu \mathrm{g} / \mathrm{ml}$ (diluted in $1.25 \%$ ethanol) and $1 \%$ DMSO were prepared as treatments.

\section{Source and culture medium of nematodes}

Culture of N2 wild strain of $C$. elegans was acquired from the College of Medicine, University of the PhilippinesManila, Ermita, Manila, Philippines. An NGM was prepared following the ingredients and protocol described by Stiernagle
(2006). The medium was pour-plated and allowed to solidify prior to the inoculation of Escherichia coli OP50 strain, which served as food for C. elegans. Cultures were incubated at $28^{\circ} \mathrm{C}$ for 18 hours allowing bacterial growth.

\section{Nematode lethality assay}

To determine the toxic concentration, a nematode lethality assay was carried out following the protocol of Qiao et al. (2014). C. elegans at L4 stage were individually picked using a worm picker and transferred into OP50-seeded NGM plates. Fifteen $C$. elegans were inoculated into each plate and subsequently treated with $300 \mu \mathrm{l}$ of each treatment. Each treatment was replicated three times. Assay plates were incubated at $20^{\circ} \mathrm{C}$. The acute and chronic lethal effects of the different treatments to C. elegans were observed every 24 hours up to 96 hours posttreatment application under $40 \times$ magnification using a stereomicroscope (Olympus, Japan). These lethal effects include being unresponsive to external stimuli, lack of muscle activity, and appearing as a straight rigid rod (Kong et al., 2014). The survival rate of $C$. elegans was determined.

\section{Pharyngeal behavior assay}

Food intake in $C$. elegans was accomplished by pharyngeal movements through pumping. The pharyngeal pumps of treated nematodes were counted per minute under $40 \times$ magnification using a stereomicroscope after 24 and 120 hours posttreatment application.

\section{Locomotion assay}

C. elegans exhibits two modes of locomotion, dwelling and roaming. The forward and backward movements (for dwelling) and body bends (for roaming) of treated nematodes were counted per minute under 40 magnification using a stereomicroscope after 24 and 120 hours posttreatment application. All nematodes used in the assay were submerged in sodium hydroxide prior to disposal.

\section{Statistical analysis}

Experimental units were laid out in a completely randomized design. Comparison between groups was done by means of one-way analysis of variance and Tukey's post-hoc test with the help of Microsoft Excel QI Macros. Differences with $p<$ 0.05 between experimental and control groups were considered.

\section{RESULTS AND DISCUSSION}

In the present work, we investigated the effects of ethanol extract of L. strigosus on the survival, food intake, and locomotion of $C$. elegans in our intention to establish the toxicological and pharmacological properties of this mushroom. To assess safety, nematode lethality assay of the varying concentrations of extract at different times of exposure was first tested. Notably, the survival of nematodes was affected by the varying concentrations of the extract of L. strigosus: as the extract concentration increased, the percentage survival decreased (Fig. 1). It can also be seen that prolonged exposure up to 96 hours showed a decrease in the percentage survival of nematodes, which clearly indicates a chronic lethal effect of the extract. Therefore, the survival of nematodes was affected by the extract of L. strigosus in a concentration- and time-dependent manner. However, none of the 


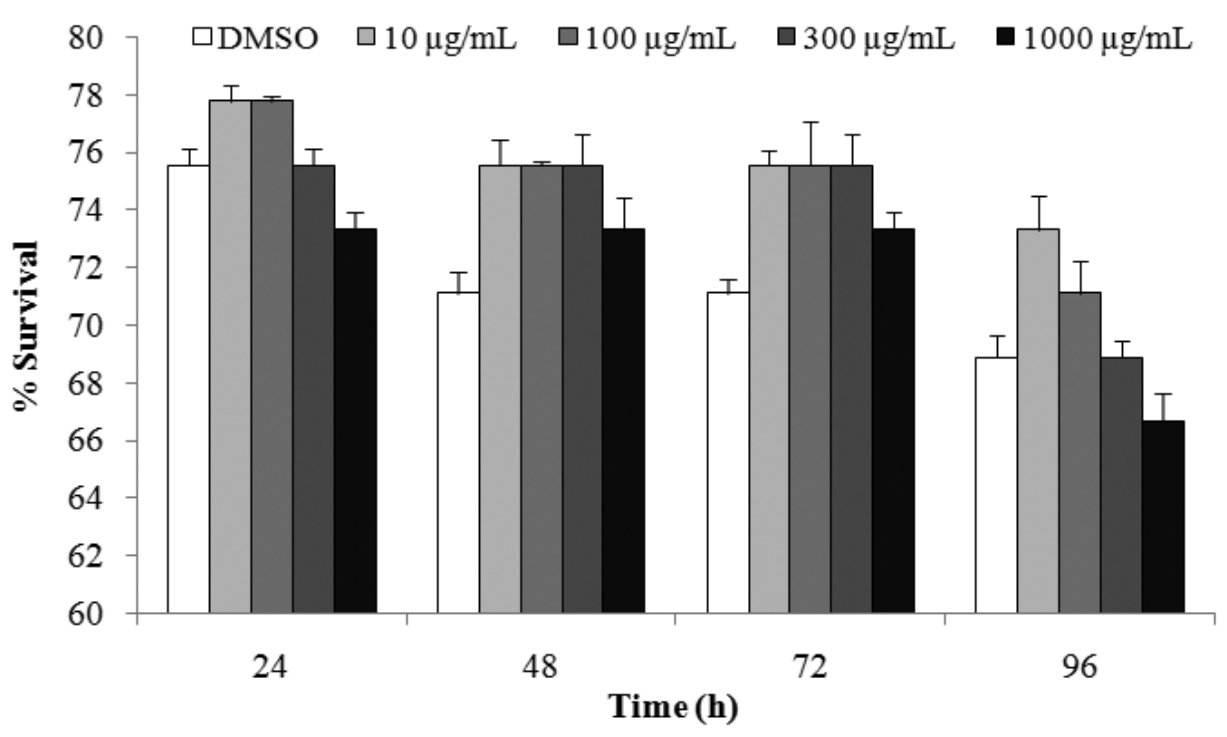

Figure 1. Survival rate of C. elegans in varying concentrations of $L$. strigosus ethanol extract at 24, 48, 72, and 96 hours posttreatment exposure.

tested extract concentrations showed 50\% lethality; thus, the $\mathrm{LC}_{50}$ value was no longer calculated. On the other hand, the control DMSO also demonstrated low toxicity on the nematode, but still had a high percentage survival. Hence, the varying concentrations of extract and controls used in this study are considered safe to proceed to bioactivity assays.

Similar to the obtained data, the water extract of fermented mycelia of Cordyceps sobolifera was also considered safe, as no abnormal behaviors were observed in C. elegans (Lin et al., 2018). Moreover, a polysaccharide from Dictyophora indusiata was not only regarded as safe but also increased the survival rate of C. elegans (Zhang et al., 2016). On the contrary, some edible mushrooms showed toxic effects or nematicidal properties. For instance, Stadler et al. (1994) reported that the fatty acids isolated from Pleurotus pulmonarius displayed toxic effects against $C$. elegans. In addition, a high nematicidal property (82\%-99\% mortality) against Haemonchus contortus nematode was exhibited by specific strains of edible mushrooms, including Pleurotus eryngii, Pleurotus cornucopiae, Pleurotus ostreatus, and Lentinula edodes (Comans-Pérez et al., 2014). Thus, the previous and present works suggest that the lethal effects of mushrooms against nematodes may vary depending on the species, strains, extraction methods, and the active compounds or metabolites they contain.

After establishing the safety, we next examined the effects of the varying concentrations of L. strigosus extract on the behavior of $C$. elegans, particularly the pharyngeal pumping rate and the dwelling and roaming activity. Pharyngeal pumping behavior correlates with the intake of food, OP50 bacteria, from the environment into the intestine of $C$. elegans. Figure 2 shows the pharyngeal pumping rate of $C$. elegans at 48 and 120 hours posttreatment exposure (hpte). In both observation periods, the pumping rate of $C$. elegans decreased as the concentration of extract increased. However, the pumping rate was markedly increased after 120 hours of exposure. The analysis revealed that pumping rates of all extract-treated nematodes were significantly lower compared to DMSO. The results of the present study strongly suggest the appetite-suppressing effect of the extract. On the contrary, serotonin increased the pharyngeal pumping rate of C. elegans (Srinivasan et al., 2008).

To determine how the extract affects the food-exploiting (dwelling) movement of the nematodes, the number of forward and backward movements (reversal locomotion) was counted. Notably, the reversal locomotion rate of C. elegans increased in the increasing concentration of the extract (Fig. 3). In both observation periods, the extract at $1,000 \mu \mathrm{g} / \mathrm{ml}$ recorded the highest reversal locomotion rate. The analysis revealed that $300 \mu \mathrm{g} / \mathrm{ml}$ and 1,000 $\mu \mathrm{g} / \mathrm{ml}$ were comparable after 48 hours of exposure. However, at 120 hpte, there was an increase in reversal locomotion rates at 10 $\mu \mathrm{g} / \mathrm{ml}$ and $100 \mu \mathrm{g} / \mathrm{ml}$. Fujiwara et al. (2002) reported that the adult wild-type (N2 strain) spent about $75 \%$ in the dwelling mode and $25 \%$ in the roaming mode on OP50 E. coli. In this study, however, the nematodes spent less time in the dwelling mode particularly at the later period of exposure. These results confirmed the ability of the L. strigosus ethanol extract to suppress the appetite of the nematodes, which may suggests potential neurological effects that caused them to suppress their appetite.

On the other hand, the number of body bends (roaming) was also counted to determine the food-seeking behavior of C. elegans. Similar to reversal locomotion, the increasing concentration of the extract increased the bending locomotion rates of nematodes (Fig. 4). The analysis showed that the effect of the $1,000 \mu \mathrm{g} / \mathrm{ml}$ extract was significantly different from all other treatments, except $300 \mu \mathrm{g} / \mathrm{ml}$ at $48 \mathrm{hpte}$. The results of the present study can be compared to the study of Kim et al. (2010), who reported the effect of taurine as an antiobesity agent in nematodes. They found that the nematodes treated with taurine traveled longer distances than the untreated ones and this positive effect of taurine on mobility may contribute to the reduction of lipid accumulation and fat storage in C. elegans. According to Srinivasan et al. (2008), just like in mammals, the feeding behavior of $C$. elegans is regulated by extrinsic and intrinsic factors, and obesity is not 


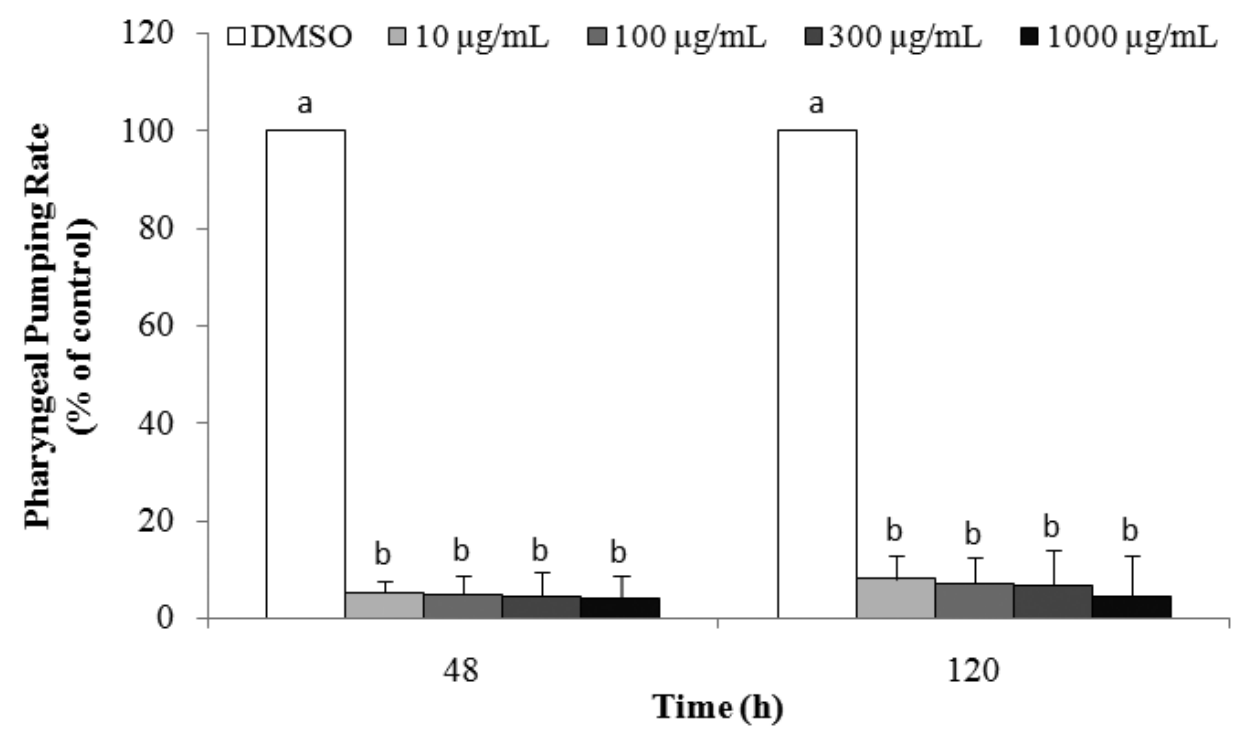

Figure 2. Pharyngeal pumping rate (\% of control) of C. elegans in varying concentrations of L. strigosus ethanol extract at 48 and 120 hours posttreatment exposure. Each value represents means of triplicate tests $(n=$ 3). Means having the same superscript letters in each time of exposure are not significantly different from each other at $5 \%$ level of significance.

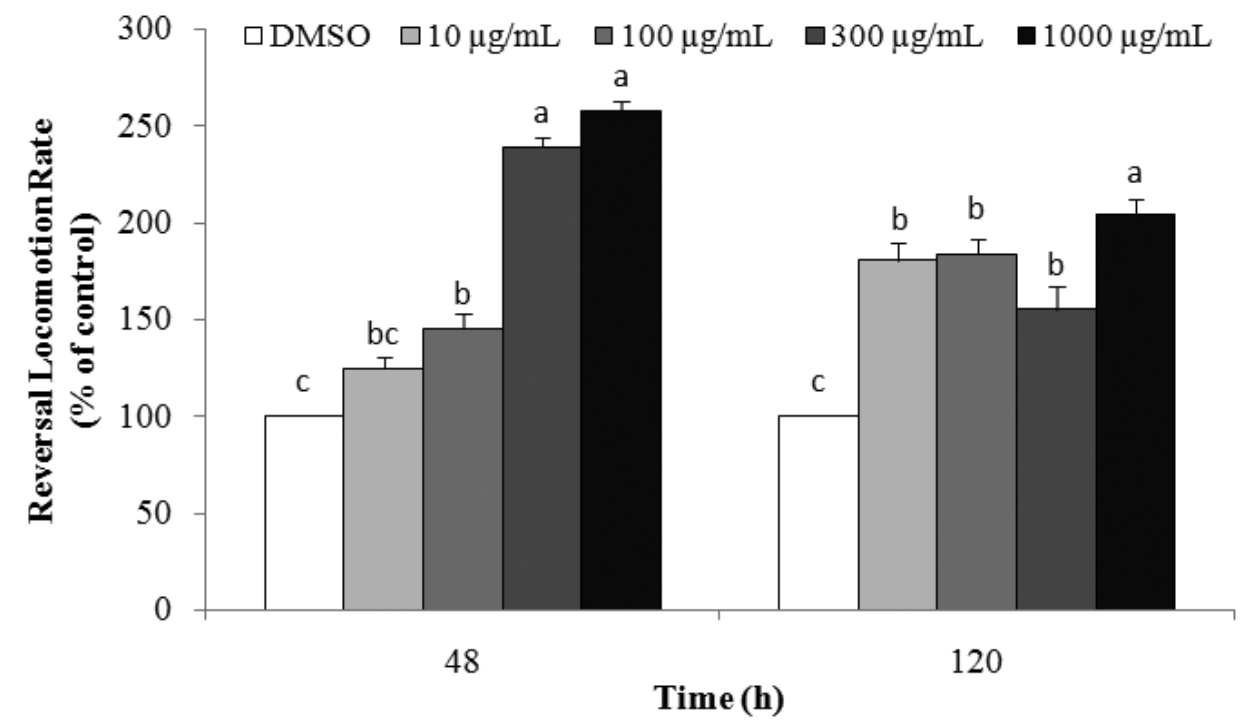

Figure 3. Dwelling locomotion (\% of control) of C. elegans in varying concentrations of $L$. strigosus ethanol extract at 48 and 120 hours posttreatment exposure. Each value represents means of triplicate tests $(n=3)$. Means having the same superscript letters in each time of exposure are not significantly different from each other at $5 \%$ level of significance.

exclusively determined by feeding behavior. Feeding behavior and fat metabolism are coordinated but independent responses of the nervous system to the perception of nutrient availability (Srinivasan et al., 2008). However, the inconsistencies were reduced, if not eliminated, in the present study, by seeding the same amount of OP50 E. coli in every replicate of all treatments. The risk of starvation is therefore reduced, if not eliminated, because of the presence of equivalently plenty food for the nematodes in all replicates of all treatments.

Previous studies demonstrated the role of cyclic guanosine monophosphate (cGMP) pathway in appetite control and metabolism and the GUCY2C-hormone axis as the center of endocrine regulation of central appetite mechanisms and paracrine control of intestinal epithelial cell homeostasis (Davis et al., 2017; Valentino et al., 2011). Elimination of GUCY2C expression in mice would disrupt appetite regulation by impairing satiation, thereby producing hyperphagia related to comorbidities, such as obesity and metabolic syndrome (Valentino et al., 2011). In mice and humans, food consumption is the first physiological stimulus that induces the secretion of prouroguanylin into the circulation. Proteolysis liberates uroguanylin which binds to GUCY2C receptor in the hypothalamus and in turn produces cGMP upon its activation to suppress feeding. 


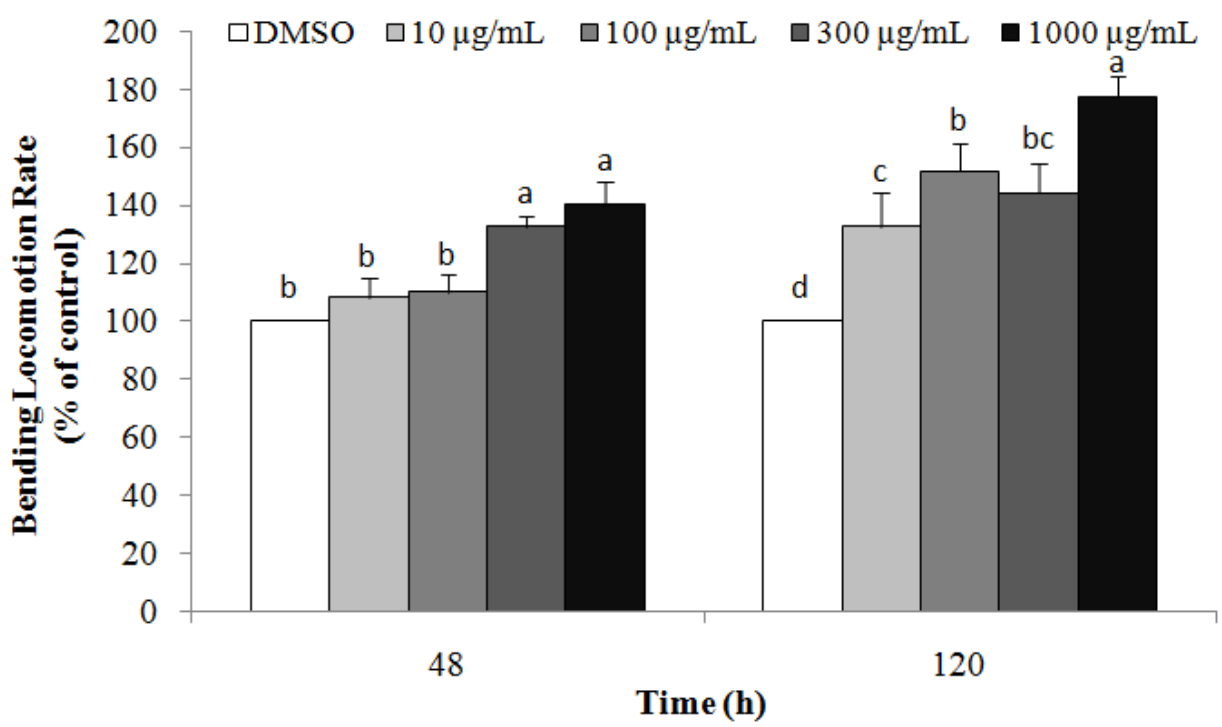

Figure 4. Roaming locomotion (\% of control) of C. elegans in varying concentrations of L. strigosus ethanol extract at 48 and 120 hours posttreatment exposure. Each value represents means of triplicate tests $(n=3)$. Means having the same superscript letters in each time of exposure are not significantly different from each other at $5 \%$ level of significance.

In C. elegans, cGMP is a key mediator of quiescence (You et al., 2008). Elimination of cGMP signaling in C. elegans causes loss of appetite regulation and quiescence, excess consumption of nutrients, and accumulation of fat. Because of its role in appetite control and other functions, cGMP has become a target for drug development. For example, sildenafil that inhibits degradation of cGMP to treat erectile dysfunction has protective effects in weight gain on a highfat diet (Ayala et al., 2007; Mitschke et al., 2013).

In our previous work, we reported that flavonoids are one of the chemical constituents of the fruiting body extract of $L$. strigosus (Dulay and Pamiloza, 2018). Marranzano et al. (2018) reported that flavonoids from dietary and herbal plants showed beneficial effects on the prevention and treatment of obesity and related metabolic disorders. In addition, higher consumption of flavonoids and weight gain are inversely related (Cases et al., 2015). Flavonoids increase nitric oxide levels in mice aorta (Benito et al., 2002), and nitric oxide activates soluble guanylyl cyclase, thereby increasing intracellular cGMP concentrations (Rizzo et al., 2010). On the other hand, inhibition of appetite which can lead to weight loss can be carried out by the proopiomelanocortin (POMC) neurons by secreting $\alpha$-melanocyte-stimulating hormone and containing receptors for serotonin and leptin (Havel, 2001). Song et al. (2019) stated that flavonoids induce satiety by affecting the AgRP and POMC neurons. It was also mentioned that nutrient absorption is modulated by flavonoids by inhibiting the action of amylase.

\section{CONCLUSION}

Altogether, the effects of $L$. strigosus ethanol extract on the pharyngeal pumping rate and locomotion of $C$. elegans were studied. The increasing concentration of extract decreased the pharyngeal pumping rate and increased both the dwelling and roaming locomotion of $C$. elegans, which suggest the appetitesuppressing effect of the extract. This effect of L. strigosus extract is one of the signature effects of antiobesity agents in C. elegans, indicating a promising potential of this mushroom as a natural and effective remedy to prevent obesity. Lipid-reducing effect of the mushroom extract and its mechanisms will be further investigated by our team in order to confirm the present claim.

\section{ACKNOWLEDGMENTS}

The authors are grateful to the College of Medicine, University of the Philippines Manila, Ermita, Manila, Philippines, for providing cultures of N2 wild strain of C. elegans and E. coli OP50 strain.

\section{CONFLICT OF INTEREST}

All the authors declare that they have no conflicts of interest for this work.

\section{FUNDING}

None.

\section{REFERENCES}

Antipatis VJ, Gill TP. Obesity as a global problem. In Bjorntorp $\mathrm{P}$ (ed.). International textbook of obesity, John Wiley \& Sons Ltd, Hoboken, NJ, pp 1-22, 2001.

Ashrafi K. Obesity and the regulation of fat metabolism. 2007 May 3. In: WormBook: The Online Review of C. elegans Biology [Internet] Pasadena (CA): WormBook; 2005-2018. Available from: https://www.ncbi. nlm.nih.gov/books/NBK19757/

Ayala JE, Bracy DP, Julien BM, Rottman JN, Fueger PT, Wasserman DH. Chronic treatment with sildenafil improves energy balance and insulin action in high fat-fed conscious mice. Diabetes, 2007; 56(4):1025-33.

Benito S, Lopez D, Saiz MP, Buxaderas S, Sanchez J, PuigParellada P, Mitjavila MT. A flavonoid-rich diet increases nitric oxide production in rat aorta. Br J Pharmacol, 2002; 135:910-6.

Cases J, Romain C, Dallas C, Gerbi A, Cloarec M. Regular consumption of Fiit-ns, a polyphenol extract from fruit and vegetables frequently consumed within the mediterranean diet, improves metabolic ageing of obese volunteers: a randomized, double-blind, parallel trial. Int J Food Sci Nutr, 2015; 66:120-5. 
Colquitt JL, Pickett K, Loveman E, Frampto GK. Surgery for weight loss in adults. Cochrane Database Syst Rev, 2014; 8(8):CD003641.

Comans-Pérez R, Aguilar-Marcelino L, Mendoza de Gives P, Sánchez J, López-Arellano M, Singh M. In vitro lethal capability of ten strains of edible mushrooms against Haemonchus contortus (Nematoda) infective larvae. In Proceedings of the 8th International Conference on Mushroom Biology and Mushroom Products (ICMBMP8). 2014; (12):557-62.

Davis K, Cheong MC, Park JS, You YJ. Appetite Control in C. elegans. In: Harris RBS, editor. Appetite and Food Intake: Central Control. 2nd ed. Boca Raton (FL): CRC Press/Taylor \& Francis; 2017. Chapter 1. PMID: 28880514.

De Silva DD, Rapior S, Hyde KD, Bahkali AH. Medicinal mushrooms in prevention and control of diabetes mellitus. Fungal Divers, 2012; 56:1-29.

Do QD, Angkawijaya AE, Tran-Nguyen PL, Huynh LH, Soetaredjo FE, Ismadji S, Ju YH. Effect of extraction solvent on total phenol content, total flavonoid content, and antioxidant activity of Limnophila aromatica. J Food Drug Anal, 2014; 22(3):296-302.

Dulay RMR, Garcia EJB. Optimization and enriched cultivation of Philippine (CLSU) strain of Lentinus strigosus (BIL1324). Biocatal Agric Biotechnol, 2017; 12:323-8.

Dulay RMR, Pamiloza DG. Proximate composition and bioactivities of hairy sawgill mushroom, Lentinus strigosus (BIL 1324) from the Philippines. Int J Biol Pharm Allied Sci, 2018; 7(3):361-9.

Dulay RMR, Rivera AGC, Garcia EJB. Mycelial growth and basidiocarp production of wild hairy sawgill Lentinus strigosus, a new record of naturally occurring mushroom in the Philippines. Biocatal Agric Biotechnol, 2017; 10:242-6.

Fujiwara M, Sengupta P, McIntire SL. Regulation of body size and behavioral state of $C$. elegans by sensory perception and the EGL-4 cGMP-dependent protein kinase. Neuron, 2002; 36:1091-102.

Hashmi S, Wang Y, Parhar RS, Collison KS, Conca W, AlMohanna F, Gaugler R. A C. elegans model to study human metabolic regulation. Nutr Metab. 2013; 10(1):31.

Haslam DW, James WP. Obesity. Lancet, 2005; 366(9492):1197-

209.

Havel PJ. Peripheral signals conveying metabolic information to the brain: short-term and long-term regulation of food intake and energy homeostasis. Exp Biol Med (Maywood). 2001; 226(11):963-77.

Kim HM, Do CH, Lee DH. Characterization of taurine as antiobesity agent in C. elegans. J Biomed Sci, 2010; 17(Suppl 1):S33.

Kong C, Yehye WA, Rahman, NA, Tan MW, Nathan S. Discovery of potential anti-infectives against Staphylococcus aureus using a Caenorhabditis elegans infection model. BMC Complement Altern Med, $2014 ; 14: 4$

Lau DC, Douketis JD, Morrison KM, Hramiak IM, Sharma AM, Ur E. 2006 Canadian clinical practice guidelines on the management and prevention of obesity in adults and children [summary]. Can Med Assoc J (Practice Guideline, Review), 2007; 176(8):S1-13.

Lin QY, Long LK, Zhuang ZH, Wu LL, Wu SL, Zhang WM. Antioxidant activity of water extract from fermented mycelia of Cordyceps sobolifera (Ascomycetes) in Caenorhabditis elegans. Int J Med Mushrooms, 2018; 20(1):61-70.

Mak Y, Nelson LS, Basson M, Johnson CD, Ruvkun G. Polygenic control of Caenorhabditis elegans fat storage. Nat Genet, 2006; 38:363-8.

Marranzano M, Ray S, Godos J, Galvano F. Association between dietary flavonoids intake and obesity in a cohort of adults living in the Mediterranean area. Int J Food Sci Nutr, 2018; 69:1020-9.

McKay RM, McKay JP, Avery L, Graff JM. C. elegans: a model for exploring the genetics of fat storage. Dev Cell, 2003; 4(1):31-42.

Mitschke MM, Hoffmann LS, Gnad T, Scholz D, Kruithoff K, Mayer P, Haas B, Sassmann A, Pfeifer A, Kilic A. Increased cGMP promotes healthy expansion and browning of white adipose tissue. FASEB J, 2013; 27(4):1621-30.
Mohamed GA, Ibrahim SRM, Elkhayat ES, El Dine RS. Natural anti-obesity agents. Bulletin of Faculty of Pharmacy, Cairo University, Giza, Egypt, 2014

Poulain M, Doucet M, Major GC, Drapeau V, Sériès F, Boulet LP, Tremblay A, Maltais F. The effect of obesity on chronic respiratory diseases: pathophysiology and therapeutic strategies. CMAJ, 2006; 174(9):1293-9.

Qiao Y, Zhao Y, Wu Q, Sun L, Ruan Q, Chen Y, Wang M, Duan J, Wang D. Full toxicity assessment of GenkwaFlos and the underlying mechanism in nematode Caenorhabditis elegans. PLoS One, 2014; 9(3):e91825.

Rizzo NO, Maloney E, Pham M, Luttrell I, Wessells H, Tateya S, Daum G, Handa P, Schwartz MW, Kim F. Reduced NO-cGMP signaling contributes to vascular inflammation and insulin resistance induced by high-fat feeding. Arterioscler Thromb Vasc Biol, 2010; 30(4):758-65.

Song D, Cheng L, Zhang X, Wu Z, Zheng, X. The modulatory effect and the mechanism of flavonoids on obesity. J Food Biochem, 2019; 43(8):e12954.

Srinivasan S, Sadegh L, Elle IC, Christensen AGL, Faergeman NJ, Ashrafi K. Serotonin regulates C. elegans fat and feeding through independent molecular mechanisms. Cell Metabolism, 2008; 7:533-44.

Stadler M, Mayer A, Anke H, Sterner O. Fatty acids and other compounds with nematicidal activity from cultures of Basidiomycetes. Planta Med. 1994; 60(2):128-32.

Stiernagle T. Maintenance of C. elegans, WormBook, ed. The $C$. elegans Research Community, WormBook. 2006.

Tsai AG, Wadden TA, Volger S, Sarwer DB, Vetter M, Kumanyika S, Berkowitz RI, Diewald L, Perez J, Lavenberg J, Panigrahi ER, Glick HA. Cost-effectiveness of a primary care intervention to treat obesity. Int J Obes, 2013; 37(1):S31-7.

Valentino MA, Lin JE, Snook AE, Li P, Kim GW, Marszalowicz G, Magee MS, Hyslop T, Schulz S, Waldman SA. A uroguanylin-GUCY2C endocrine axis regulates feeding in mice. J Clin Invest, 2011; 121(9):357888.

World Health Organization. Obesity and overweight. World Health Organization, Giza, Egypt, 2008.

Yen K, Le TT, Bansal A, Narasimhan SD, Cheng K, Tissenbaum HA. A comparative study of fat storage quantitation in nematode Caenorhabditis elegans using label and label-free methods. PLoS One, 2010; 5(9):e12810.

You YJ, Kim J, Raizen DM, Avery L. Insulin, cGMP, and TGFbeta signals regulate food intake and quiescence in C. elegans: A model for satiety. Cell Metab, 2008; 7(3):249-57.

Zhang J, Shi R, Li H, Xiang Y, Xiao L, Hu M, Ma F, Ma CW, Huang Z. Antioxidant and neuroprotective effects of Dictyophora indusiata polysaccharide in Caenorhabditis elegans. J Ethnopharmacol, 2016; 192:413-22.

Zheng J, Vasselli JR, King JF, King ML, We W, Fitzpatrick Z, Johnson WD, Finley JW, Martin RJ, Keenan MJ, Enright FM, Greenway FL. Using Caenorhabditis elegans as a model for obesity pharmacology development. Am J Ther, 2014; 23(6):e1363-70.

How to cite this article:

Aquino YK, Dulay RM, Kalaw S. Effect of Lentinus strigosus extract on the food intake and locomotion of N2 wild strain Caenorhabditis elegans as model for obesity. J Appl Pharm Sci, 2020; 10(12):023-028. 